\title{
Survey of Different Methodologies Used in Phonocardiogram Signal Analysis
}

\author{
Simarjot Kaur Randhawa \\ Research Scholar \\ EIED, Thapar University \\ Patiala, India
}

\author{
Mandeep Singh \\ Assitant Professor \\ EIED, Thapar University \\ Patiala, India
}

\begin{abstract}
Heart sounds give us information about the state of the heart Heart diseases can be detected at an earlier stage by analyzing the heart sounds. In this paper, detailed discussion of various methodologies that have been used earlier to analyze the heart sounds has been carried out. Comparison has been done on the basis of methodology used and the performance achieved.
\end{abstract}

\section{Keywords}

Heart sounds, Systolic, Diastolic, Murmurs

\section{INTRODUCTION}

The technique of listening to heart sounds using stethoscope is called cardiac auscultation. Abnormalities in the heart sounds start appearing much earlier than the symptoms. Therefore, this technique can be used to detect various heart disorders at an earlier stage. The graphic recording of heart sounds is known as phonocardiogram (PCG). PCG signal is generated due to mechanical activity of heart, blood flow, vibration of chamber valves, opening and closing of valves. It is mainly recorded using electronic stethoscope and the signal is displayed on the computer screen. The heart sounds usually occur at the time of closure of major heart valves [1]. With each heart beat, normal heart produces two distinct sounds- often described as 'lub-dub' [1]. The first heart sound (lub), also known as S1, is caused by the closure of atrioventricular valves. When the blood from atria flows to ventricles, these valves allow unidirectional blood flow i.e. from atria to ventricles and block the reverse blood flow back to atria from ventricles. The second heart sound (dub), also known as S2, is caused due to closure of semilunar valves. These valves release blood into the pulmonary and systemic circulation systems and prevent backflow of blood. Third (S3) and fourth (S4) heart sounds are rare heart sound which are not normally audible but may be visible on the graphic recording. S3 is caused due to rushing of blood from atria to ventricles. S4 is produced when blood is forced into stiff or enlarged ventricle. S1 and S2 are called Fundamental Heart Sounds (FHS).

The period from beginning of one heart beat to the next one is known as the cardiac cycle. In other words, the interval between start of S1 to start of next S1 is called cardiac cycle. The region between S1 and starting of S2 of same heart cycle is called systole and the region between S2 and starting of S1 of next heart sound cycle is called diastole. Sometimes we may hear unusual sound during the heartbeat cycle. They may be whooshing or swishing noise. These are called murmurs. They are generally high-frequency, noise like sounds that are produced as a result of turbulent blood flow [2]. Intensity, frequency content, split information, time relations, location of murmurs etc. are some of the features of PCG signal which can be helpful in detecting heart valve diseases, if any, and the condition of the functioning of heart. We may classify heart murmurs as systolic murmur, diastolic murmur or continuous murmur. Murmurs which occur in systole are called systolic murmurs and which occur in diastole are called as diastolic murmurs. Murmurs which occur continuously throughout the cardiac cycle are known as continuous murmurs. Diastolic murmurs, which occur during diastole, are mostly associated with ventricular relaxation and filling as they originate after S2 i.e. second heart sound. The cause of occurrence of such murmurs may be due to aortic or pulmonic valve regurgitation or by mitral or tricuspid valve stenosis. Systolic murmurs, which occur during diastole i.e. between $\mathrm{S} 1$ and $\mathrm{S} 2$, are associated with mechanical systolic and ventricular ejection or regurgitation across the atrio-ventricular valves [3]. Many studies classify different heart diseases based on the PCG signal.

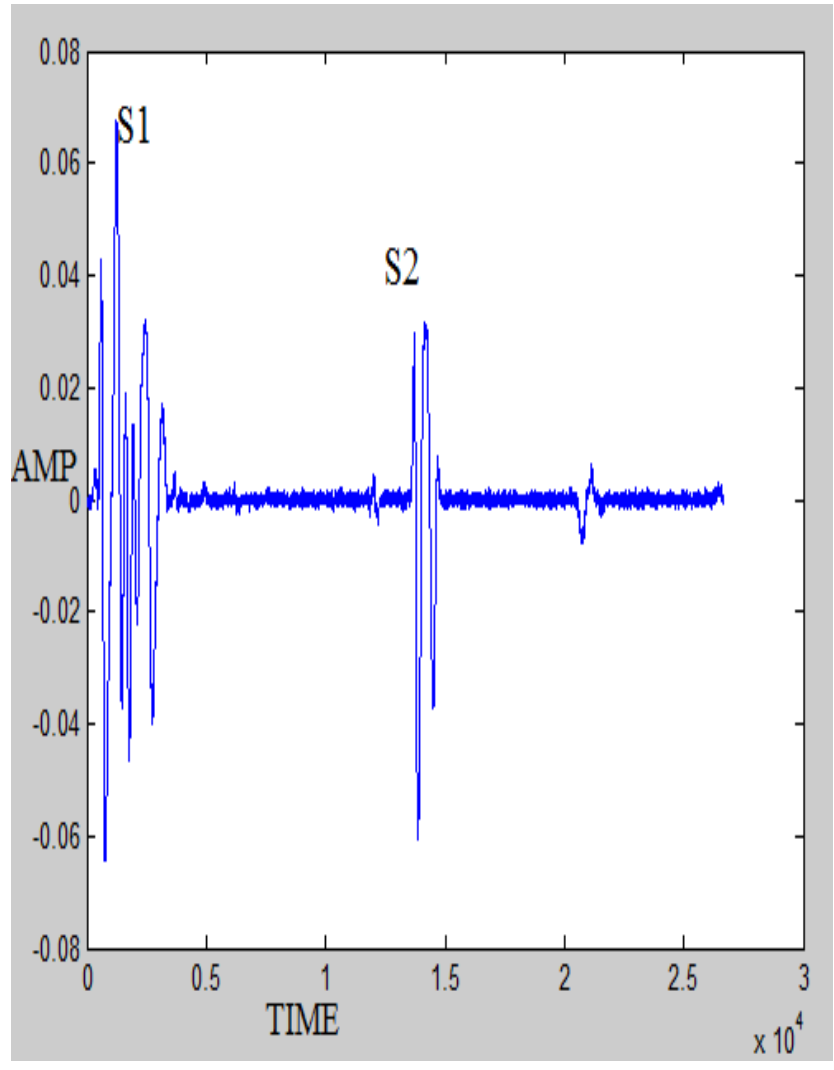

Figure 1: A normal PCG signal showing S1 and S2 heart components.

\section{COMPARISON}

Different methodologies used to analyze the phonocardiogram signal have been compared which include discrete wavelet transform, Continuous wavelet transform, Hilbert transfer, Short term Fourier transform etc. and a comparison table has been made. 
Table 1. Comparison table of different methodologies used in studies.

\begin{tabular}{|c|c|c|c|c|c|}
\hline Year & Methodology & Contributions & $\begin{array}{l}\text { Performance } \\
\text { achieved }\end{array}$ & $\begin{array}{l}\text { ECG } \\
\text { gating } \\
\text { used }\end{array}$ & Comments \\
\hline 2005 & $\begin{array}{l}\text { Short Time Fourier } \\
\text { Transform (STFT) [4] }\end{array}$ & $\begin{array}{l}\text { Detection of heart sounds } \\
\text { (S1 \& S2) and systolic } \\
\text { murmur. }\end{array}$ & $\begin{array}{l}100 \%-\mathrm{S} 1 \\
97 \%-\mathrm{S} 2\end{array}$ & Yes & $\begin{array}{l}20-70 \% \text { of systolic segment was } \\
\text { selected for murmur detection } \\
\text { analysis. }\end{array}$ \\
\hline 2006 & $\begin{array}{l}\text { Cardiac Sound } \\
\text { Characteristic } \\
\text { Waveform (CSCW) } \\
{[5]}\end{array}$ & $\begin{array}{ll}\text { Arrhythmia, } & \text { Mitral } \\
\text { Stenosis, } & \text { Aortic } \\
\text { Regurgitation } & \end{array}$ & & No & $\begin{array}{l}\text { Adaptive Threshold Value was } \\
\text { calculated using Fuzzy C-Means. }\end{array}$ \\
\hline 2007 & $\begin{array}{l}\text { Phonospectrogram } \\
{[6]}\end{array}$ & 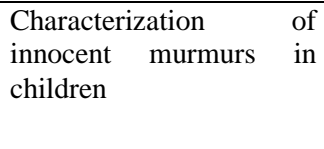 & $\begin{array}{l}90 \%-\text { Sensitivity } \\
91 \%-\text { Specificity }\end{array}$ & No & $\begin{array}{l}\text { Innocent murmurs have lower } \\
\text { frequencies and frequency spectrum } \\
\text { with more harmonic structure as } \\
\text { compared to pathological murmurs. }\end{array}$ \\
\hline 2008 & Fuzzy clustering [3] & $\begin{array}{l}\text { Location/ detection of } \\
\text { systolic murmur. }\end{array}$ & $\begin{array}{l}80 \% \text { - Detection } \\
73 \% \text { - Sensitivity } \\
100 \% \text { - Specificity }\end{array}$ & No & $\begin{array}{l}\text { An amplitude and frequency invariant } \\
\text { signal characteristic has been proposed } \\
\text { to distinguish cardiac murmur. }\end{array}$ \\
\hline 2011 & $\begin{array}{l}\text { Discrete Wavelet } \\
\text { Transform [7] }\end{array}$ & High noise robustness & $\begin{array}{l}92 \% \text { - Noise-free } \\
90 \% \text { - with white noise } \\
\text { and } 10 \mathrm{~dB} \text { SNR and } \\
\text { for impulse noise up to } \\
0.3 \mathrm{~s} \text { duration. }\end{array}$ & No & No segmentation used. \\
\hline 2011 & $\begin{array}{ll}\text { Adaptive } & \text { Singular } \\
\text { Spectrum } & \text { Analysis } \\
\text { (ASSA) } & \\
{[8]} & \end{array}$ & $\begin{array}{l}\text { Extraction of different } \\
\text { types of murmur signal. }\end{array}$ & $\begin{array}{l}\text { Correlation between } \\
\text { separated components, } \\
\text { heart sound and } \\
\text { murmur signal }\end{array}$ & No & $\begin{array}{l}\text { Two sounds are separated perfectly } \\
\text { even if they are temporally overlapped } \\
\text { over a region. }\end{array}$ \\
\hline 2011 & $\begin{array}{l}\text { Digital Subtraction } \\
\text { Phonocardiography } \\
{[9,10]}\end{array}$ & Murmurgram & Visual differences & Yes & $\begin{array}{l}\text { Normal murmurgram is fairly flat and } \\
\text { low in intensity }\end{array}$ \\
\hline 2011 & $\begin{array}{l}\text { CSP (Color } \\
\text { Spectrographic } \\
\text { Phonocardiography) } \\
{[11]}\end{array}$ & $\begin{array}{l}\text { Distinguish pathological } \\
\text { and innocent murmurs in } \\
\text { children }\end{array}$ & Visual differences & Yes & $\begin{array}{l}\text { Pathological systolic murmurs have } \\
\text { lower frequency and shorter duration } \\
\text { than innocent systolic murmurs }\end{array}$ \\
\hline 2011 & $\begin{array}{l}\text { Hilbert Transfer } \\
\text { Envelope [12] }\end{array}$ & $\begin{array}{l}\text { Classification of normal } \\
\text { and abnormal PCG } \\
\text { signals }\end{array}$ & Accuracy-91.3\% & No & $\begin{array}{l}\text { Energy of each segment ( } 0.01 \mathrm{~s} \text { time) is } \\
\text { calculated and energy plot is obtained. }\end{array}$ \\
\hline 2012 & $\begin{array}{lr}\text { CWT } & \text { (Continuous } \\
\text { Wavelet } & \text { Transform) } \\
{[13]} & \end{array}$ & Scalogram & Visual differences & No & $\begin{array}{l}\text { Temporal and frequency rates are } \\
\text { considered to quantify the differences } \\
\text { between various PCG signals. }\end{array}$ \\
\hline 2012 & $\begin{array}{ll}\text { Wavelet } & \text { Packet } \\
\text { transform [14] } & \end{array}$ & $\begin{array}{l}\text { Distinguish } \\
\text { mitral stenosis, mitral } \\
\text { regurgitation, } \\
\text { aortic stenosis, and aortic } \\
\text { regurgitation }\end{array}$ & Accuracy- 96.94\% & No & $\begin{array}{l}\text { Wavelet packet entropy was used to } \\
\text { calculate or generate features from } \\
\text { PCG recordings which are } \\
\text { discriminative in nature. }\end{array}$ \\
\hline 2013 & $\begin{array}{ll}\text { Improved } & \text { EMD } \\
\text { (Empirical } & \text { Mode } \\
\text { Decomposition) } & {[15]}\end{array}$ & $\begin{array}{l}\text { PCG signal denoising } \\
\text { and extraction of } 1^{\text {st }} \text { and } \\
2^{\text {nd }} \text { heart sounds }\end{array}$ & $\begin{array}{l}\text { S1- } 100 \% \\
\text { S2- } 99.48 \% \\
\text { overall accuracy- } \\
99.74 \%\end{array}$ & No & $\begin{array}{l}\text { Signal is decomposed into several } \\
\text { different frequency bands from high } \\
\text { frequencies to low frequencies. }\end{array}$ \\
\hline 2013 & $\begin{array}{ll}\text { Wavelet } & \text { Packet } \\
\text { transform [16] } & \end{array}$ & $\begin{array}{l}\text { Distinguish normal heart } \\
\text { sound, mitral } \\
\text { regurgitation, } \begin{array}{r}\text { aortic } \\
\text { regurgitation and aortic } \\
\text { stenosis. }\end{array} \\
\end{array}$ & Accuracy- $97.56 \%$ & Yes & $\begin{array}{l}\text { Multi-level basis selection (MLBS) } \\
\text { was proposed so that the most } \\
\text { informative bases of a wavelet packet } \\
\text { decomposition tree is preserved. }\end{array}$ \\
\hline 2013 & $\begin{array}{l}\text { Feature extraction in } \\
\text { time domain, } \\
\text { frequency domain and } \\
\text { statistical features[17] }\end{array}$ & $\begin{array}{l}\text { A new feature, mean } 12 \text {, } \\
\text { is proposed which is the } \\
\text { maximum of the mean in } \\
\text { systolic and diastolic } \\
\text { regions. }\end{array}$ & $\begin{array}{l}\text { Bayes Net- } 91.6667 \% \\
\text { Naïve Bayes-93.33\% } \\
\text { SGD-91.6667\% } \\
\text { Logit boost- } 88.3333 \%\end{array}$ & No & $\begin{array}{l}\text { Classification of normal and abnormal } \\
\text { heart sounds is done. }\end{array}$ \\
\hline
\end{tabular}

\section{DISCUSSION}

In 2005, Seiger et al used STFT for detection of first and second heart sounds ( 1 1 \& S2). Also, for murmur analysis he used $20-70 \%$ of the systolic segment as heart signals S1 and S2 sometimes partially overlap systolic murmur [4]. In 2006, Jiang et al proposed analytical model which was based on single DOF. Characteristic waveforms were extracted using this model from heart sounds to detect heart disorders. The diagnostic parameters [T1, T2, T11, T12] were obtained by 
FCM clustering method. For cardiac sound characteristic waveform (CSCW) scattergram and histogram were plotted for [T1, T2] and [T11, T12] [5]. In 2007, Noponen et al differentiated innocent murmurs and pathological murmurs using phono-spectrographic analysis. The study showed that innocent murmurs are characterized by lower frequency and have a frequency spectrum with more harmonic structure as compared to pathological cases [6]. In 2008, Nigam et al proposed a method to locate systolic murmurs in the PCG signal based on their visual simplicity which is independent of their absolute amplitude and frequency characteristics. Fuzzy clustering approach was used and it showed that number of fuzzy clusters can be used to determine presence of cardiac murmurs. The degree of membership of simplicity value in clusters was used to locate systolic murmurs. The accuracy achieved in detecting systolic murmurs was $80 \%$ [3]. In 2011, Yuenyoung et al proposed an algorithm in which cardiac cycles were extracted from heart sounds with different heart rates. Using this algorithm there was no need to label the individual Fundamental Heart Sounds (FHS) for extraction of individual heart cycles. Discrete wavelet transform was used for feature extraction of cardiac sounds and classification was done using neural network bragging predictors [7]. In 2011, Sanei et al used Adaptive Singular Spectrum Analysis (ASSA) to separate murmurs from the recorded heart sounds. The major advantage of this technique is in perfectly separating the two sounds even in temporally overlapped regions [8]. In 2011 Akbari et al proposed new analytical technique known as Digital Subtraction Phonocardiography (DSP). It is based on the principle that the murmurs are random in nature but the FHS are deterministic in nature. A murmurgram was constructed by simply taking the difference between the acoustic emissions of two successive heart beats. It was found that the murmurgram should be flat between the FHS for normal cases but it is not the case with abnormal cases [9, 10]. In 2011, Sarbandi et al proposed a new technique known as Color Spectrographic Phonocardiography (CSP). It was used to detect and characterize heart murmurs [11]. In 2011, Xiao-Juan et al extracted S3, S4, the first split and the second split and relocated the starting and ending of S1 and S2. It was based on the slopes of envelop of Hilbert Transfer Envelope after energy segmentation. In this research the overall accuracy of $91.95 \%$ was achieved for features extraction. 25 significant clinical features were introduced and SVM classifier was used for classification. The overall accuracy of $91.3 \%$ was achieved in case of classification. The result showed that features including clinical signification is of signification for enhancing the accurate rate of Phonocardiogram classification [12]. In 2012, Debbal et al used Continuous Wavelet Transform (CWT) to study normal and abnormal Phonocardiogram (PCG) signals. Features in time-frequency domain were extracted and their scalograms exhibited noticeable morphological differences in terms of duration and spectral composition of sounds [13]. In 2012, Safara et al introduced new entropy to analyze heart sounds and it was shown that it was feasible to use this entropy in classification of five types of heart sounds and murmurs. The heart sounds considered for classification consisted of one normal heart sound and four common murmurs: Aortic regurgitation, Mitral regurgitation, Aortic stenosis, and Mitral stenosis. Heart sound analysis was done by wavelet packet transform. To derive various feature vectors the entropy was calculated. Five types of classification were performed and the accuracy of the generated features was evaluated. The best results were achieved using Bayes Net as a classifier with an accuracy of $96.94 \%$. The results showed that the proposed wavelet packet entropy was effective for heart sounds classification [14]. In 2013, Sun et al combined Improved EMD
(Empirical Mode Decomposition) and Shannon energy envelope algorithm for extraction of S1 and S2 components and achieved a high accuracy of $99.74 \%$ [15]. In 2013, Safara et al proposed multi-level basis selection (MLBS) so that the most informative bases of the wavelet packet transform decomposition tree is preserved. It was done by removing the less informative bases. In order to do this three exclusion criteria was applied i.e. frequency range, noise frequency, and energy threshold. Classification of normal heart sound signal and three kinds of murmur signals (mitral regurgitation, aortic regurgitation and aortic stenosis) is done in this study. The results of MLBS were compared with single-level basis selection (SLBS), local discriminant basis (LDB) and best basis selection (BBS) and it was found out that using MLBS higher accuracy of $97.56 \%$ was achieved [16]. In 2013, Singh et al proposed a new feature, mean 12 , which is the maximum of the mean in systolic and diastolic region to classify signal into two classes i.e. normal and murmur signal. 23 features in time domain, frequency domain, statistical and cepstrum were extracted and out of all the features only 5 optimal features were selected for classification. Four different classifiers were used and the accuracies were calculated. Also, 5 fold cross validation was used. The classifiers used were Bayes Net, Naïve Bayes, SGD and Logit boost and the accuracies achieved were $91.6667 \%, 93.3333 \%, 91.6667 \%$ and $88.3333 \%$ respectively. Highest accuracy of $93.3333 \%$ was achieved using the Naïve Bayes classifier [17].

\section{CONCLUSION}

In this paper various methodologies which have been used in analyzing the phonocardiogram signal have been compared. Performance of each methodology has also compared. Maximum accuracy of $99.74 \%$ was achieved by Shannon energy envelop algorithm in extraction of S1 and S2 heart sound components. Due to the denoising of the signal the results achieved were better. Wavelet based PCG signal analysis achieved accuracy of $90 \%-97.56 \%[7,13,14,16]$.

\section{FUTURE SCOPE}

3 class classification of the phonocardiogram signal can be done i.e. normal signal, systolic murmur signal and diastolic murmur signal. Hybrid classifier can also be used for classification with higher accuracy.

\section{REFERENCES}

[1] Cromwell, L., Weibell, F.J., Pfeiffer, E.A. 2010. Biomedical Instrumentation and Measurements. Pearson Education, Second Edition.

[2] Safara, F., Doraisamy, S., Azman, A., Jantan, A. and Ranga S. 2013. Diagnosis of Heart Valve Disorders through Trapezoidal Features and Hybrid Classifier. International Journal of Bioscience, Biochemistry and Bioinformatics, Volume 3, No.6.

[3] Nigam, V. and Priemer R. A simplicity-based fuzzy clustering approach for detection and extraction of murmurs from the phonocardiogram. IOP publishing physiological measurement, Physiol. Meas. Volume 29. 33-47.

[4] El-Segaier, M., Lilja, O., Lukkarinen, S., Sornmo L., Sepponen, R. and Pesonen, E. R. 2005. Computer based detection and analysis of Heart Sound and Murmur. Annals of Biomedical Engineering. Volume 33, No. 7. 937-942.

[5] Jiang, Z. and Choi, S. 2006. A cardiac sound characteristic waveform method for in-home heart disorder monitoring 
with electric stethoscope. Expert Systems with Applications, Volume 31. 286-298.

[6] Noponen, A.L., Lukkarinen, S., Angerla, A. and Sepponen, R. 2007. Phono-spectrographic analysis of heart murmur in children. BioMed Central, BMC Pediatrics.

[7] uenyong, S., Nishihara, A., Kongprawechnon, W. and Tungpimolrut, K.. 2011. A framework for automatic heart sound analysis without segmentation. BioMedical Engineering OnLine, Volume 10.

[8] Sanei, S., Ghodsi, M. and Hassani, H. 2011. An adaptive singular spectrum analysis approach to murmur detection from heart sounds. Elsevier, Medical Engineering \& Physics, Volume 33. 362-367.

[9] Akbari, M.A., Hassani, K., Doyle, J. D., Navidbakhsh, M., Sangargir, M., Bajelani, K. and Ahmadi, Z. S. 2011. Digital Subtraction Phonocardiography (DSP) applied to the detection and characterization of heart murmurs. BioMedical Engineering OnLine, Volume 10, 1-14.

[10] Akbari, M.A., Hassani, K., Doyle, J. D., Navidbakhsh, M., Sangargir, M., Bajelani, K. and Foroughi, M. 2011. Separating the random murmur component of the phonocardiogram from the underlying deterministic heart sounds applied to Digital Subtraction Phonocardiography (DSP). 18th Iranian Conference on BioMedical Engineering (ICBME).

[11] Sarbandi, R. R., Doyle, J. D., Navidbakhsh, M., Hassani, K. and Torabiyan, H. 2011. A color spectrographic phonocardiography (CSP) applied to the detection and characterization of heart murmurs: preliminary results. BioMedical Engineering OnLine, Volume 10.

[12] Xiao-Juan, H., Jia-Wei, Z., Gui-Tao, C., Hong-Hai, Z. and Hao, L. 2011. Feature extraction and choice in PCG based on Hilbert Transfer. 4th International Congress on Image and Signal Processing.

[13] Debbal, S.M. and Bereksi-Reguig, F. 2012. Detection of Differences of the Phonocardiogram Signals by Using the Continuous Wavelet Transform Method. Biomedical Soft Computing and Human Sciences, Volume 18, No.2. 73-81.

[14] Safara, F., Doraisamy, S., Azman, A., Jantan, A. and Ranga, S. 2012. Wavelet Packet Entropy for Heart Murmur Classification. Hindawi Publishing Corporation. Advances in Bioinformatics, Volume 2012. 6 pages.

[15] Sun, H., Chen, W. and Gong J. 2013. An Improved Empirical Mode Decomposition-Wavelet Algorithm for Phonocardiogram Signal Denoising and its Application in the First and Second Heart Sound Extraction. 6th International Conference on Biomedical Engineering and Informatics (BMEI 2013).

[16] [16] Safara, F., Doraisamy, S., Azman, A., Jantan, A. and Ramaiah, A. R. A. 2013. Multi-level basis selection of wavelet packet decomposition tree for heart sound classification. Elsevier. Computers in Biology and Medicine, Volume 43. 1407-1414.

[17] Singh, M. and Cheema A. 2013. Heart Sounds Classification using Feature Extraction of Phonocardiography Signal. International Journal of Computer Applications. Volume 77. 